\title{
ASSESSMENT OF KNOWLEDGE, ATTITUDE AND PRACTICES ON DEPRESSION AND ASSOCIATED FACTORS AMONG MEKELLE UNIVERSITY COLLEGE OF HEALTH SCIENCES STUDENTS IN, MEKELLE CITY, ETHIOPIA 2010/11
}

\author{
Kalayou Kidanu, Mekuria Kassa*, Ashenafi Damtie, Alemayehu Bayray, Haftu Berhe, Balem \\ Demtsu \\ Department of Nursing, College of Health Science, Mekelle University.
}

\section{ABSTRACT}

Background: Depression goes by many names: Depression, "the blues," biological depression, major depression or clinical depression. But it all refers to the same thing: feeling sad and depressed for weeks or months on end (not just a passing blue mood). This feeling is most often accompanied by feelings of hopelessness, a lack of energy (or feeling "weighed down"), and taking little or no pleasure in things that gave you joy in the past. The lifetime prevalence of major depressive episode ranges $5-17 \%$. Women are more at risk of severe depression. Women are usually affected between the age of 35 and 45 and men over 55 . Mental and emotional symptoms are expressed differently at different ages. Adolescents are at a vital transition stage between childhood and adulthood. Their bodies are changing fast with strong feelings of independence and sexuality emerging.

Objective: was to assess Knowledge, Attitude, and Practices of depression and associated factors among the students of Mekelle University College of Health Sciences.

Methodology: Institutional based cross sectional study design was conducted using a stratified random sampling method from Feb. 28-Jun 23/ 2011. The study was conducted at Mekelle University, College of health sciences students. The sample size was 290 students. The study area was Mekelle University, College of Health Sciences.

Result: Out of the total 290 respondents, $46.9 \%$ were developed depressions. The leading cause to develop depression was an academic problem, separation from family and financial problem. There is an association between sex and age. There is also an association of depression status with the department and batch; whereas religion and ethnicity have no association.

Conclusion-there is new depression due to associated factors such as academic problem $40.4 \%$, financial problem $25.1 \%$ \& separation from family $23.5 \%$ in Mekelle University, College of health sciences students 2003 . In addition, to that biological, genetics \& Sico-social factors are included.

Key Words: Knowledge, Attitude, Practices, and depression

\section{INTRODUCTION}

Depression is a mood disorder that causes a persistent feeling of sadness and loss of interest. Also called major depressive disorder or clinical depression, it affects how you feel, think and behave and can lead to a variety of emotional and physical problems. You may have trouble doing normal dayto-day activities, and sometimes you may feel as if life isn't worth living. ${ }^{[1]}$

Depression goes by many names -- depression, "the blues," biological depression, major depression.

*Corresponding author:

Email: Mekuriakassa85@yahoo.com

http://dx.doi.org/10.20530/IJTA $32 \quad 69-76$

ISSN 2320-138X (c) 2016
But it all refers to the same thing: feeling sad and depressed for weeks or months on end (not just a passing blue mood). This feeling is most often accompanied by feelings of hopelessness, a lack of energy (or feeling "weighed down"), and taking little or no pleasure in things that gave you joy in the past. A person who's depressed just "can't get moving" and feels completely unmotivated to do just about anything. Even simple things -- like getting dressed in the morning or eating -- become large obstacles in daily life. People around them -- their friends and family -- notice the change too. Often they want to help, but just don't know how. ${ }^{[2]}$

Depression affects approximately 19 million Americans, or $9.5 \%$ of the population in any given one-year period. At some point in their lives, 10\%$25 \%$ of women and $5 \%-12 \%$ of men will likely become clinically depressed. In fact, it affects so 


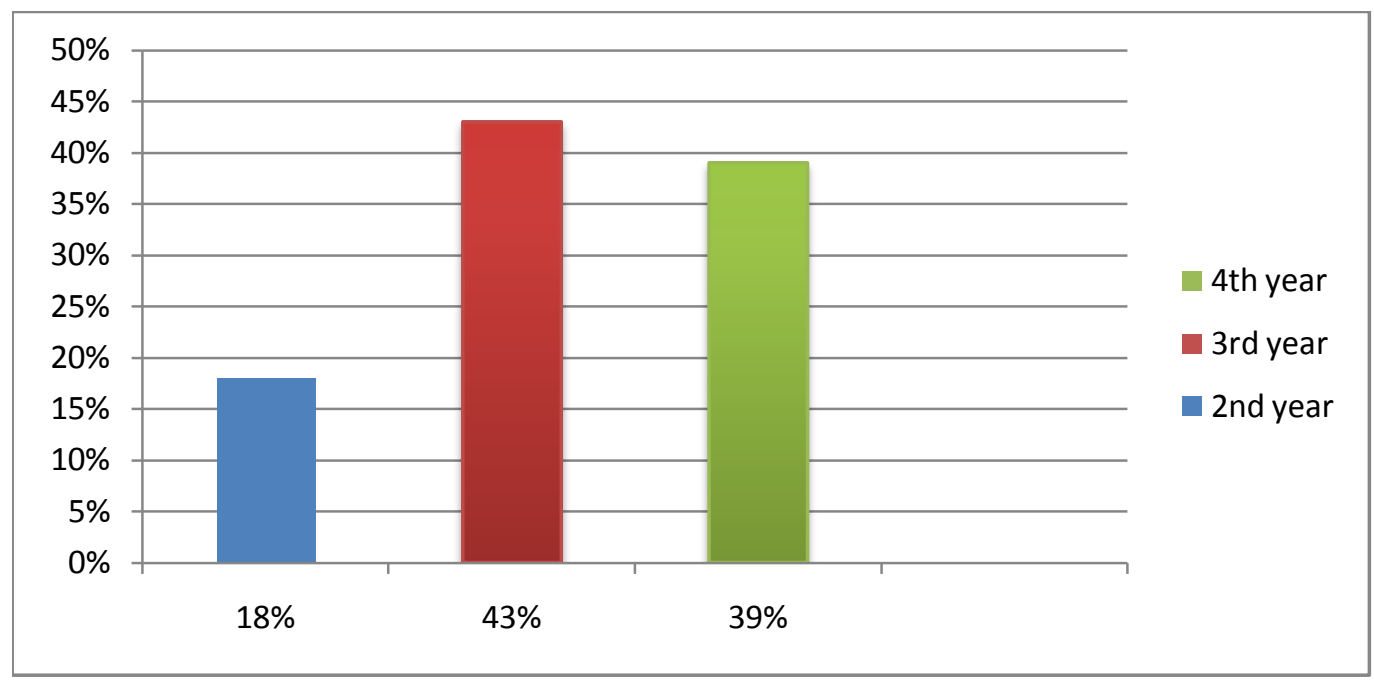

The majorty of the study population were third year students, which were 43\%.[Fig.-1]

Fig-1: Distribution Mekelle University, College of health sciences students from their batch, 2010/11.

many people that it is often referred to as the "common cold" of mental illness. Depression not only causes suffering to those who are depressed, but it also causes great difficulty for their family and friends who often do not know how to help. Clinical depression affects all aspects of a person's life. It impairs our ability to sleep, eat, work, and get along with others. It damages our self-esteem, selfconfidence, and our ability to accomplish everyday tasks. People who are depressed find daily tasks to be a significant struggle. They tire easily, yet cannot get a good night's sleep. They have no motivation and lose interest in activities that were once enjoyable. Depression puts a dark, gloomy cloud over how we see ourselves, the world and our future. This cloud cannot be willed away, nor can we ignore it and have it magically disappear. ${ }^{[3]}$

Completed suicide occurs in up to $15 \%$ of individuals with severe Major Depressive Disorder. The first episode may occur at any age from childhood to old age, the onset may be either acute or insidious, and the duration varies from a few weeks to many months. The average age at onset is in the mid-20s. Of people with severe depressive illnesses, 10 to 15 per cent will commit suicide. Suicide accounts for I in 100 deaths. The majority of those who die in this way are men. ${ }^{[4,5]}$

The lifetime prevalence of major depressive episode ranges (23\%) had life-time depression. Prevalence of current Major Depressive Disorder (MDD), Dysthymia and "Double depression" were
$2.6 \%, 1.0 \%$ and $0.6 \%$, respectively, and for Depression NOS 6.3\%. Literatures indicate that the likelihood of depressive disorder occurrence in individuals in their lifetime diagnosis of depression were similar in 2006 (15.7\%) and 2008 (16.1\%) in the USA. With women consistently reported as having a twofold lifetime prevalence of depression, and a greater likelihood of seeking help for depression than men. ${ }^{[6,7]}$

An episode of depression is serious enough to require treatment occurs in about one in four women and one in ten men at some point in their lives. About two-thirds of adults will at some time experience depressed mood of sufficient severity to interfere with their normal activities. A study done in the UK, in the year 2000, the point prevalence of depression among those 16-74 years of age was $2.6 \%$ when the less specific and broader category of mixed depression and anxiety was included; these figures rose dramatically to $11.4 \%$ (males $9.1 \%$, females $13.6 \%$. Weissman et al. published the first cross-national comparison of major depression from 10 population-based surveys that administered the Diagnostic Interview Schedule to representative community samples. DSM-III criteria were used to define depression. Lifetime prevalence estimates ranged from $1.5 \%$ (Taiwan) to $19.0 \%$ (Beirut) in these studies, with the midpoints at 9.2\% (West Germany) and $9.6 \%$ (Edmonton, Canada). Twelvemonth prevalence estimates ranged from $0.8 \%$ (Taiwan) to $5.8 \%$ (Christchurch, New Zealand), with the midpoints at $3.0 \%$ (US) and $4.5 \%$ (Paris). ${ }^{[8,9]}$ 
Prevalence rates have consistently been found to be $1.5-2.5$ times higher in women than in men in the age group $18-64$ years. A treatment gap appears especially wide in counties classified as low or middle income by the World Bank, where around $85 \%$ of the world's population resides. In such countries treatment rates for these disorders are suboptimal and range from 35\%-50\%. In Ethiopia, over the follow-up period, $2(0.7 \%)$ of the participant with no depression and 9(3.0\%)of the participant with major depression were reported to have died. The mortality ratio standardized for age and gender was 3.55(95\%Cl1.97-6.39). ${ }^{[10-12]}$

Depressed teenager may be hostile, grumpy, or easily lose his or her temper. Unexplained aches \&pains are also common symptoms of depression in young people. Left untreated, teen depression can lead to problems at home and school, drug abuse, self-loathing-even irreversible tragedy such as homicidal violence or suicide. The cause of adolescent depression and most teenage depression is reactive to psychosocial adversities and deprivations. ${ }^{[13]}$

Depression is the fourth leading cause of disease burden, accounting for $4.4 \%$ in the year 2000 , and it causes the largest amount of non-fatal burden, accounting for almost $12 \%$ of all total years lived with disability worldwide. Worldwide, the numbers of mentally ill people are increasing and likely to increase yet further. Mental disorders are represented in 4 of the leading ten cases of disability in the world. Though Depression, Mental and behavioral disorders account for $12 \%$ of the global burden of disability, but the mental health budgets of most countries are less than $1 \%$ of total health expenditure. Researches and studies done on depression in this area is not much in assessing the KAP and discussing the associated factor of depression. $^{[14,15]}$

The significance of the study: As there is no research done on this topic on Mekelle university students and also in the Tigray region this study findings will help policy maker and social service provider as they work with the youth and the university students. This study will use as a preliminary resource which can help future research activity.

\section{METHODOLOGY}

The study area was Mekelle University College of Health Science, is found at the City of Mekelle in Tigray region of Northern Ethiopia at a distance of
$783 \mathrm{~km}$ from the capital city, Addis Ababa. College of Health Science was established 2006 with the aim of producing medical doctors. Presently the department has started a postgraduate training program in the MSc in emergency surgery, gynecology \& obstetrics for health officer students. Institutionally based, cross sectional study was conducted. The study period was From Feb. 28-Jun 23/2011. Source population was all Mekelle University, College of Health Science students. Study subjects were all sampled students (290) from 2nd\& above year students of Mekelle University, College of Health Sciences. Since there is no available similar study found, a population prevalence of $50 \%$ was used. The following assumptions were considered $5 \%$ margin of error and $95 \%$ confidence interval. The sample size of this particular study was calculated using single population proportion formula and by adding 5\% contingency for non-responsiveness the total sample size was 290. Stratified random sampling method (SRS) was applied to each stratum based on the proportion of allocation.

The inclusion criteria were all students in the College who are volunteering to participate in the study and exclusion criteria were students who are first year, in service nursing \& post graduate students. Data was gathered from the students and proportional allocation was carried out and data were collected use of self-administer the questionnaire. Continuous follow up and supervision was conducted by principal investigator throughout the data collection period. Structured questionnaire was used for data collection of Knowledge, attitude and practices and the questionnaire was also used to collect social demographic of the study subjects.

To assure data quality, the questionnaire was initially prepared in English and then translated into Amharic version. The collected data were reviewed and checked for completeness and consistency by the principal investigator on a daily bases on the spot during the data collection time.Ethical approval of the research was obtained from an ethical review committee of Mekelle University, college of health science, department of nursing and formal letter was written from the department of nursing to each department of the college to get Co-operation. After a brief explanation of the purpose of the study, verbal consent was obtained from the patients and the confidentiality and beneficence were maintained throughout the study and not to participate or withdraw at any point from the study was respected. The confidentiality of the data was safeguarded 
during and after the data collection and no one except the principal investigator and advisor access the data. The independent variables were Age, Sex, Department, Batch, Ethnicity, Religion and the dependent variable was about depression.

Operational definitions were: Insomnia is defined as difficulty falling asleep or staying asleep, even when a person has the chance to do so, depression is defined as it is a serious medical condition in which a person feels very sad, hopeless, and unimportant and often is unable to live in a normal way

Loss of weight - reduced weight, Concentration reduced - decreased attention from a specific thing, Suicidal ideas - wish to die, with variable degree of self-harming thoughts, plans or actions psychomotor retardation - slowing down of all reaction and function. Depressive delusion - despair, blame or calamity, Bipolar disorder - characterized by mood that alternates between periods of depression and period of elation and excitable behavior. Cyclothymiacs disorder - a milder yet more in during type bipolar disorder. Seasonal affective disorder (SAD) - condition affects people during specific times or seasons of the year. Postpartum depression - A rare form of depression occurring in human within approximately one week to six months after giving birth to a child.

A major depressive episode- at least 2 weeks and typically a person with a diagnosis of the major depressive episode also experiences at least four symptoms from a list that include changes, feelings of guilt, problem thinking and making decisions and recurring thought of death or suicide. Depression, those that have at least $5 \geq$ symptoms from the following: Loss of interest Decreased sleep, Poor appetite, Significant of weight loss, Loss of energy, Guilty feeling, diminished ability to think or concentrate, depressed mood most of the day. Knowledgeable - one who has answered more than or equal to $75 \%$ of the knowledge assessing questions. Positive measure -those that have taken a measure to alleviate, depression, which will never affect their health in a bad way like by going church, reading book recreation, etc Negative measure those who alleviate depression by some measure like smoking, alcohol drinking, suicidal attempt which will affect their health. Attitude: - A settled way of thinking or feeling, typically reflected in the person's behavior. The questionnaires were checked for completeness and consistency by the principal investigator and quantitative data was first cleaned, edited, coded and entered into the computer and was analyzed using SPSS version 16.0. Frequencies and percentages were calculated to describe the findings, while Chi square(X2)was calculated for looking association among outcome variables and social demographic data.

\section{RESULT}

\section{Socio Demograpic Characterstic}

A total of 290 students was selected during the data collection period. The majority of the students (65.9\%) were in the age group 21-25. Out of 290 respondents, (74.8\%) were male. The majority of them are Tigrian134 (81.7\%), Amhara (23.8\%), Oromo (14.4\%).Among 290 respondents 237(81.7\%) were orthodox in religion and protestant accounts 37(11.7\%).[Table.1]

Table-1: socio-demographic characteristics of students of Mekelle University, College of Health Sciences, Mekelle City 2010/11.

\begin{tabular}{llcc}
\hline Variable & No & $\begin{array}{c}\text { Percent } \\
\text { (\%) }\end{array}$ \\
\hline \multirow{3}{*}{ Age } & $16-20$ & 92 & 31.7 \\
& $21-25$ & 191 & 65.9 \\
Sex & $26-30$ & 7 & 2.4 \\
& Male & 217 & 74.8 \\
Ethnicity & Female & 73 & 25.2 \\
& Tigrian & 134 & 81.7 \\
& Amara & 69 & 23.8 \\
& Oromo & 42 & 14.4 \\
Religion & Others & 48 & 25.5 \\
& Orthodox & 237 & 81.7 \\
& Protestant & 34 & 11.7 \\
& Muslim & 12 & 4.1 \\
\hline
\end{tabular}

Distribution of students by department

The highest number of students at MU-CHS

Table 2: Distribution of students of Mekelle University, College of Health Sciences by the department, Mekelle City 2010/11

\begin{tabular}{llcc}
\hline Variable & & Frequency & Percent \\
\hline \multirow{4}{*}{ Depart- } & Pharmacy & 53 & 18.3 \\
ment & Medicine & 145 & 50.0 \\
& Nurse & 24 & 8.3 \\
& Midwife & 20 & 6.9 \\
& Public & 48 & 16.6 \\
\hline
\end{tabular}


student were 145 , from the department of medicine, which is (50.0\%) among 290 selected students.[table-2]

Distribution of students by their state of depression and Knowledge, Attitude and practices towards depression

Table-3. Distribution of students of Mekelle University, college of Health Sciences by their state of depression and Knowledge, Attitude and practices, Mekelle City, 2010/11

\begin{tabular}{lcc}
\hline \multicolumn{1}{c}{ Variable } & Frequency & Percent \\
\hline Depressed & 136 & 46.9 \\
Not depressed & 154 & 53.1 \\
Total & $\mathbf{2 9 0}$ & $\mathbf{1 0 0 . 0}$ \\
Knowledgeable & 208 & 71.7 \\
not knowledgeable & 82 & 28.3 \\
Total & $\mathbf{2 9 0}$ & $\mathbf{1 0 0 . 0}$ \\
Positive attitude & 205 & 70.7 \\
Negative attitude & 85 & 29.3 \\
Total & $\mathbf{2 9 0}$ & $\mathbf{1 0 0 . 0}$ \\
Positive measure & 106 & 77.9 \\
Negative measure & 30 & 22.1 \\
Total & $\mathbf{2 9 0}$ & $\mathbf{1 0 0 . 0}$ \\
\hline
\end{tabular}

From all participants who responded the questionnaires 154 of them (53.1\%) were not depressed of those $71.7 \%$ were knowledgeable. $70.7 \%$ presented positive attitude toward depression. Among 290 respondents 106 (77.9\%) of them have taken healthy measure whenever they had depression. [table-3]
Association of depressive states with socio demographic characteristic

The study result shows sex $(p=0.035)$ and all age groups has a strong association with depressive state $(P=0.002)$. [Table-4]

Association of depressive states with department \&batch

Both departments \& batch have very strong association with individual depression state. $(p=0.00)$ and $(p=0.001)$ for batch and department respectively.[Table-5]

Association of knowledge with department and batch

The study finds out the students' department was not associated with the knowledge they have about depression, but batch has a strong association with knowledge about depression. [Table.6]

\section{Association of attitude with department and batch}

There was no association of attitude with department and batch. [Table-7]

Association of practice with department and batch

There was association of practice with the department $(p<0.05)$ but no association of practice with batch $(p>0.05)$. [Table-8]

\section{DISCUSSION}

This is the first study of Knowledge, Attitude and practices about depression among Mekelle University, College of Health Science students and

Table -4.Association of depressive statues with socio demographic characteristics of Mekelle University, College of Health Science students, Mekelle City, 2010/11

\begin{tabular}{llcccc}
\hline Variable & & \multicolumn{2}{c}{ Statues } & \multicolumn{2}{c}{ X2 Test } \\
\cline { 3 - 6 } sex & Female & Depressed & Not depressed & Chi- square & P-value \\
\cline { 3 - 5 } Age & Male & 94 & 31 & 4.433 & 0.035 \\
& $16-20$ & 31 & 123 & & \\
\multirow{5}{*}{ Ethnicity } & $21-25$ & 99 & 61 & & \\
& $26-30$ & 6 & 92 & 12.54 & 0.002 \\
& Tigray & 69 & 1 & 1.9 & \\
& Amhara & 31 & 65 & & \\
& Oromo & 29 & 38 & 0.58 \\
& Others & 17 & 13 & & \\
& Orthodox & 110 & 31 & & \\
& Protestant & 20 & 127 & & \\
& Muslim & 3 & 13 & & \\
& Catholic & 1 & 9 & & \\
& Other & 2 & 2 & & \\
\end{tabular}


Table -5. Association of depressive statues with department and Batch of Mekelle University-College of Health Sciences students, Mekelle City, 2010/11

\begin{tabular}{llcccc}
\hline Variable & & \multicolumn{2}{c}{ Status } & \multicolumn{2}{c}{ X2 test } \\
\cline { 3 - 6 } & & Depressed & $\begin{array}{c}\text { Not } \\
\text { Depressed }\end{array}$ & $\begin{array}{c}\text { Chi- } \\
\text { square }\end{array}$ & p-value \\
\hline \multirow{6}{*}{ Department } & Pharmacy & 38 & 15 & 19.47 & 0.001 \\
& Medicine & 64 & 81 & & \\
& Midwifery & 6 & 14 & & \\
& Nursing & 12 & 12 & & \\
& Public health & 16 & 32 & & \\
& 2nd & 10 & 46 & 27.75 & \\
& 3rd & 60 & 66 & & \\
\hline
\end{tabular}

Table-6.Association of Knowledge with department and Batch of Mekelle University College of Health Science students, Mekelle City, 20010/11

\begin{tabular}{llcccc}
\hline Variable & & \multicolumn{2}{c}{ Knowledge } & \multicolumn{2}{c}{ X2 test } \\
\cline { 3 - 6 } & & $\begin{array}{c}\text { Knowled- } \\
\text { geable }\end{array}$ & $\begin{array}{c}\text { Not- } \\
\text { knowledgeable }\end{array}$ & Chi- square & p-value \\
\hline \multirow{5}{*}{ Department } & Pharmacy & 43 & 10 & 5.72 & 0.22 \\
& Medicine & 105 & 40 & & \\
& Midwifery & 11 & 9 & & \\
& Nursing & 17 & 7 & & \\
Batch & Public health & 32 & 16 & 51.7 & \\
& 2nd & 19 & 37 & & \\
& 3rd & 96 & 30 & & \\
& 4th and more & 93 & 15 & & \\
\hline
\end{tabular}

the study found that the majority of respondent of $53.1 \%$ not depressed and generally held by their reason for their depressive states. Academic problem (40.4\%), financial problem (25.1\%) and separation from family $(23.5 \%)$ were the main cause for depression among the students. The study indicates a stronger association of knowledge with batch than department the reason is as the students stayed more in the college and also being involved in the health care delivery system their knowledge also increases toward depression as it is one of the public health importance. The majority of the students acknowledged the role of life events in the development of depression and nearly a forth believed that depressed students are more likely experienced academic problem, separation from family and financial problem with a student life.

The etiological importance attached to life events and deprivation early in life was consistent with other studies in East Africa among primary health workers. There was no association of attitude with department \&batch of Mekelle University, College of Health Science students. The attitude of the respondent to treatments of depression shows they believe there is more than one way of treating depression, some agreed with the statement that depression is amenable to change, most of the students agreed with the statement that depressive disorder improve without medication, and the majority felt that antidepressant usually produce a satisfactory result in the treatment of depressed patients in primary care. It is encouraging that the majority students, felt comfortable dealing with depressed patients, that this could be a useful to support depressed patient's according to study found on Knowledge, Attitude and practices pertaining to depression among primary health care in Tanzania about depression \& it found that the majority of respondents felt that rates of depression had increased in recent years believed that life events were important in the etiology of depression, 
Table-7. Association of attitude with department and Batch of Mekelle University, College of Health Science students, Mekelle City, 2010/11

\begin{tabular}{llcccc}
\hline Variable & & \multicolumn{2}{c}{ Attitude } & \multicolumn{2}{c}{ X2 test } \\
\cline { 3 - 6 } & & Good Attitude & Bad Attitude & Chi- square & p-value \\
\hline \multirow{5}{*}{ Department } & Pharmacy & 40 & 13 & 3.22 & 0.52 \\
& Medicine & 99 & 46 & & \\
& Midwifery & 14 & 6 & & \\
& Nursing & 20 & 4 & & \\
\multirow{5}{*}{ Batch } & Public health & 32 & 16 & & \\
& 2nd & 39 & 17 & 0.25 & \\
& 3rd & 91 & 35 & & \\
& 4th and more & 75 & 33 & & \\
\hline
\end{tabular}

Table-8 Association of practice with department and Batch of Mekelle University, College of Health Science students, Mekelle City, 2010/11

\begin{tabular}{llcccc}
\hline \multirow{2}{*}{ Variable } & & \multicolumn{2}{c}{ Practice } & \multicolumn{2}{c}{ X2 test } \\
\cline { 3 - 6 } & & $\begin{array}{c}\text { Healthy } \\
\text { measure }\end{array}$ & Healthy measure & Chi- square & p-value \\
\hline \multirow{6}{*}{ Department } & Pharmacy & 35 & 3 & 44.09 & 0.001 \\
& Medicine & 48 & 16 & & \\
& Midwifery & 4 & 2 & & \\
& Nursing & 11 & 1 & & \\
& Public health & 7 & 9 & 11.69 & 0.30 \\
& 2nd & 8 & 2 & & \\
\hline
\end{tabular}

\& generally held positive views about pharmacological and psychological treatment of depression, prognoses and their own involvement in the treatment of depressed patients. The study is limited by the sample size of primary care workers, and by the fact that they were all working in DARESALAAM so the result may not be generalized to the rest of the country.

\section{CONCLUSION}

There is unrecognized depression due to associated factors such as academic problem $40.4 \%$, financial problem $25.1 \%$ and separation from family $23.5 \%$. In Mekelle University, the College of Health Sciences students' 2011.In addition, that biological factor, genetic factors \& social factors are included. For all participant $71.7 \%$ were knowledgeable,70.7\% presented positive attitude( i.e. going to religion area, reading books, recreation, etc.)106 (77.9\%) of them have taken healthy measure whenever they had depression. In line with our study differs from others studies warrens further research. In the contradictory, could be because depressive illness is under diagnose and undertreated in primary health care setting throughout the world. Generally positive attitudes towards depression found in this study of primary care workers in Tanzania may be capitalized and continuing professional development of primary health care workers in the detection and management of depression. There is a high, but unrecognized burden of postnatal depression among mothers in the northern Malawi.

It can therefore be concluded that: (i) Based on the result found in this study there is more to work on increasing the awareness toward depression for students. Also the practices to treat depression among students have to be discussed within students or with social workers to avoid a negative practice like alcohol consumption, chewing chat and sometimes suicidal attempt, (ii) It is better to that the university open psycho social department that will work to solve students' problems, and to work jointly with the psychiatry department in increasing Knowledge, building better attitude also helping 
students to apply healthy practices to solve their problem, (iii) As the study shows' being separated from family is one and the main cause of depression, it was being better if students can be assigned a nearby university from their residential area with their family \& (iv) Finally, we recommend that such kinds of research better to study in different universities of the country.

\section{REFERENCE}

1. MayoClinic.org, [internet]. Minnesota: Mayo Foundation for Medical Education and Research [updated Jul 22, 2015, cited April, 2016] available, from: $\quad$ http://www.mayoclinic.org http://dx.doi.org/10.1002/hup.2526

2. John M. Grohol,, psychcentral.com[internat] PsychCentral [updated 18 Apr 2016, cited Apr 22,2016]. Available from; http://psychcentral.com. http://dx.doi.org/10.1037/e542182009-020

3. Kessler RC, Chiu WT, Demler O, Walters EE. Prevalence, severity, and comorbidity of twelvemonth DSM-IV disorders in the National Comorbidity Survey Replication (NCS-R). Archives of General Psychiatry, 2005 Jun;62(6):617-27. http://dx.doi.org/10.1001/archpsyc.62.6.617

4. Mentalhealth.com[internet] Internet Mental Health, Canadian. [updated 2015, cited Apr,2016]. Available from:http://www.mentalhealth.com/home/dx/major depressive.html

5. netdoctor.co.uk[internet] UK, depression-and-suicidein-men [updated 14.01.2015 cited 2016] http://www.netdoctor.co.uk/conditions/depression/

6. William CR, Tara WS, Laura AP. www.cdc.gov/mmwr,[internet] Mental Illness Surveillance in the US: September 02, 2011[cited Apr, 2016]. Available from http://www.cdc.gov/mmwrdults. http://dx.doi.org/10.1016/s0270-6644(11)70370-8
7. K. Wilhelm, K. Roy, P. Mitchell, S. Brownhill and; G. Parker, et al; Gender difference in depression risk and coping factor in clinical sample.Acta Psychiatrical Scandinavica Vol 106 issue 1 (p) 45-53 July 2002. http://dx.doi.org/10.1034/j.1600-0447.2002.02094.x

8. Esds.ac.uk [internat] the national center for health and social care, adult psychiatric morbidity survey, [updated 2007, cited Apr, 2016]. Available from:www.esds.ac.uk/doc/6379/mrdoc. http://dx.doi.org/10.1016/j.socscimed.2014.09.025

9. Ronald C.Kessler, Evelyn J. Bromet, The epidemiology of depression across culture. Annua review publisher 2013;119-138. http://dx.doi.org/10.1146/annurevpublhealth-031912-114409

10. Gavin A, Richi p, Ingmar S. lifetime risk of depression restricted to a minority or waiting for most?. Nov 2005 187(6) 495-496. The British Journal of Psychiatry 2005 Nov. http://dx.doi.org/10.1192/bjp.187.6.495

11. Tim A Bruckner, Richard M, Gordon S, Jangho $Y$, Dan $C$, Jodi $\mathrm{M}$, et al, The mental health workforce gap in low and middle income countries: a needs based approach. The bulletin of the WHO 2011;89:184-194. http://dx.doi.org/10.2471/blt.10.082784

12. Souci M, Martin P, Atalay A, Dereje K, Robert S, Nick $\mathrm{G}$, et al, Outcome of major depression in Ethiopia The British Journal of Psychiatry Aug 2006, 189(3) 241. http://dx.doi.org/10.1192/bjp.bp.105.013417

13. Slitwristsandbrokenhearts.tumblr.com [internet] slitwrisandbrokenhearts, Depression in teens \{updated Jun, 2015, Cited Apr, 2016\}, available from: https;//www. Slitwristsandbrokenhearts.tumblr.com

14. Ustun TB, Ayuso-Mateos JL, Chatterji S, et al Global burden of depression disorders in the year 2000. The British Journal of psychiatry (2004) 184:386-392). http://dx.doi.org/10.1192/bjp.184.5.386

15. Syed Amin Tabish et al, Mental Health: Neglected for far Too Long. www. Academia.edu/JK-Practitioner 2005;12(1):34-38 